\title{
Mountain Biodiversity Day 2021 - biodiversity and pandemic
}

\author{
Chris Walzer \& Guido Plassmann
}

Keywords: COVID-19, biodiversity protection, resilient environments, protected areas

\section{Abstract}

On 13 January 2021, the French Ministry of the Environment in cooperation with ALPARC, UNEP and the Permanent Secretariat of the Alpine Convention organized the virtual Mountain Biodiversity Day. The event gathered together experts in the field of mountain biodiversity and political representatives from mountain regions all over the world in order to stress the importance of mountain biodiversity within the Post-2020 Global Biodiversity Framework, especially in the context of the on-going pandemic and discussions on building back better. The Alpine session of the event, introduced by Guido Plassmann, was moderated by Chris Walzer and focused on the link between biodiversity and zoonoses - a major challenge for environmental policies worldwide. The topic is developed by the short text which follows.

\section{Introduction}

Against the backdrop of a relentlessly warming planet, atmospheric carbon dioxide breaching 400ppm, and some one million species threatened with extinction over the next few decades, a new coronavirus has catapulted across the ever-evolving interfaces between humans and wild places, relentlessly spreading disease and bringing immense suffering and death to the most remote corners of our planet. This dramatic global situation is caused by a virus that previously existed on the other side of the human-wildlife interface, and the disease that it causes was unknown and still unnamed at the beginning of 2020 .

This pandemic is primarily not about bat soup, pangolins or even specific viruses, but all about our interactions with nature, and our exploitation and destruction of it. It is about the interfaces - these edges of destruction - between humans, wildlife and nature in general, and the super-interfaces we create in urban centres with the commercial trade of wildlife for consumption. Along with climate change, biodiversity loss and raging inequities and injustice, COVID-19 is just another symptom of an ailing planet and has starkly reminded us of the basic fact: human, animal, plant and environmental health and well-being are all intrinsically connected.

To limit the impacts of the next spillover event, we need a holistic One Health approach, as outlined in the Berlin Principles on One Health, which the Wildlife Conservation Society elaborated with the German Federal Foreign Office just a few weeks before the start of the present pandemic. The Berlin Principles update the Manhattan Principles from 2004, which first coined the term One Health for a broader public, and reconnect the health of humans, animals and ecosystems in an economic and socio-political context.

As the world anxiously welcomes COVID-19 vaccines, we mustn't fool ourselves into complacency. A vaccine, while critically important from a public health perspective, is but a stop-gap measure in the larger context of the multitude of global crises such as cli- mate change, biodiversity loss, global inequities and injustices that we are currently facing.

One of the most important and proven foundational solutions to these global crises are protected areas. For centuries, Indigenous Peoples and local communities have been setting aside areas that have important natural, cultural and spiritual values. In recent decades, governments have created more and larger protected areas on land and sea, and there is strong evidence that effectively designed and managed protected areas are key to the conservation of biodiversity, climate mitigation and sustaining local livelihoods.

However, many protected areas are not well managed, due to a lack of staff or insufficient legal possibilities for intervention, and often they do not represent the full diversity of ecosystems. Additionally, many protected areas are simply too small to be viable and resilient in the long term, especially under the light of climate change. Furthermore, they are frequently sited in areas that do not adequately represent the originally targeted biome and ecosystems and, moreover, fail to avoid land-use conflicts in our predominantly multi-use landscapes.

In a few words, protected areas must be located in the right places, be large and interconnected enough to sustain viable populations of key species and key functions, operate within a robust legislative framework, and have reliable, long-term funding.

\section{The Alps}

Globally, the Alps are one of the most intensively used and populated mountain ranges. The mountain range is in parts dominated by settlements, growing tourist infrastructures, and is criss-crossed by European transit routes. Protected areas are embedded in intensively used multi-use landscapes, leading to spatial and functional fragmentation. Preserving altitudinal gradients intact is key in the conservation of resilient and functional mountain landscapes. Consequently, it is not sufficient to protect the highest elevations while ignoring the rampant land-use changes across the val- 
ley floors. If we want protected areas in the Alps to remain strongholds of biodiversity and long-term refuges for species, we must protect entire altitudinal gradients.

Protection also provides numerous ecosystem services, including regulating climate and air quality, providing water, energy and food, while also providing sociocultural benefits to the large urban centres adjacent to the Alpine region and beyond. It is crucial to guarantee that protected areas are connected across the Alps - ecologically and functionally - and valued appropriately by all sectors, especially by the highly urbanized belt surrounding the Alps.

For more than 20 years, ALPARC has worked together with protected areas, local and regional stakeholders, ministries and multilateral partners (such as the Alpine Convention) on the location and especially the interconnectivity of protected areas. Research institutions and NGOs constitute important additional partners that provide the necessary scientific basis which informs management, policy and legislation. The central goal is to protect Alpine biodiversity for generations to come, sustainably.

With protected areas as the backbone, a lot of work and planning, often with the help of the Alpine Space Programme (INTERREG), Germany and France, have been done for the Alpine area; methodologies and maps have been produced to connect natural spaces better and make habitat protection more efficient. Political awareness about the topic has increased. Both the Alpine Convention and the EUSALP approach have recognized ecological connectivity linked to long-term spatial planning as one of the most promising ways to protect Alpine biodiversity and enhance resiliency.

\section{Biodiversity protection - a crucial invest- ment for the future}

To say, in July 2021, that emerging zoonotic pathogens, climate change and biodiversity loss have significant implications for both public health and economic stability is perhaps the most tremendous understatement of this still-young century. Returning to zoonotic-origin pathogen spillovers: the costs of many individual recent major outbreaks, of SARS, MERS and Ebola for example, are estimated in the tens of billions of Euros. However, when all is tallied, the economic devastation caused by COVID-19 will certainly be orders of magnitude greater: in the tens of trillions of Euros. The ongoing and future costs of climate change and biodiversity loss appear simply unimaginable.

Multilateralism based on increased global collaboration and solidarity constitutes the basis for a future healthy planet. To successfully address and prevent future pandemics and secure our health and wellbeing, we need tight trans-sectoral cooperation between governments, robustly funded multilateral institutions, and strengthened collaborations with conservation NGOs who work on the spillover and conservation frontlines. Similarly, and equally importantly, crosssectoral investments in nature, climate protection and nature-based solutions must occur at regional levels. The Alpine protected areas and ALPARC constitute the largest network of nature-based solutions for climate change and biodiversity protection within the Alpine Convention. Clearly, we must stop ignoring nature right now and accept once and for all that nature is not and should never be considered a cheap externality in our unconstrained patterns of production and consumption. It is painfully apparent that addressing the complex interactions of human, animal and environmental health requires environmentally inclusive, just and shared values that heed landscapeand society-level issues.

As the pandemic continues to rage across the planet, we must urgently recognize and value the foundational importance of intact and resilient environments for our health and wellbeing. We need biodiversity conservation, climate change mitigation and bealth, in and across all policies and administrations, fundamentally. Existing siloed approaches are unacceptable and must become a thing of the past.

\section{Some recent publications}

https://www.bmu.de/publikation/alpine-nature2030-creating-ecological-connectivity-for-generations-to-come/

https://www.alpine-space.eu/projects/alpbionet2030/en/home

http://alparc.org/de/alpine-resources/atlas-alpbionet 2030

https://www.sciencedirect.com/science/article/ pii/S0048969720364494

https://www.frontiersin.org/articles/10.3389/ fvets.2020.582983/full

\section{Authors}

\section{Chris Walzer}

Executive Director Health Wildlife Conservation Society, Bronx, NY, USA. Research Institute of Wildlife Ecology; University of Veterinary Medicine Vienna, Austria

\section{Guido Plassmann}

Director ALPARC - The Alpine Network of Protected Areas.
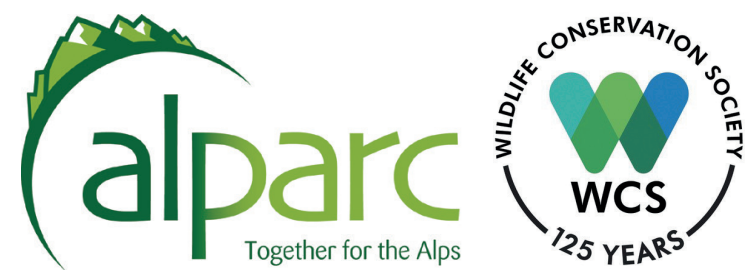

vetmeduni 